\title{
Se a estratégia é prática, quem são seus praticantes?
}

\author{
If strategy is practice, who are the practitioners?
}

Diego Maganhotto Coraiola ${ }^{[a]}$, Samir Adamoglu de Oliveira ${ }^{[b]}$, Sandro Aparecido Gonçalves ${ }^{[c]}$

[a] Doutorando em Administração pela Universidade Federal do Paraná - UFPR, Professor na Faculdade Cenecista de Campo Largo - FACECLA, Curitiba - PR, Brasil, e-mail: dcoraiola@gmail.com

[b] Doutorando em Administração pela Universidade Federal do Paraná - UFPR, Curitiba - PR, Brasil, e-mail: samiroliveira09@hotmail.com

[c] Doutor em Administração pela Fundação Getúlio Vargas - FGV/SP, Professor do PPGADM da Universidade Federal do Paraná UFPR, Curitiba - PR, Brasil, e-mail: sag2@uol.com.br

\section{Resumo}

Discordando do individualismo metodológico que permeia a maioria das pesquisas sobre o papel e a atuação dos estrategistas na 'Estratégia como Prática', o presente artigo analisa quem são os estrategistas organizacionais, empreendendo discussão e crítica pautadas em pesquisas publicadas seguindo tal vertente. Esse argumento é desenvolvido principalmente oferecendo evidências empíricas para o que se defende, mediante estudo de caso qualitativo sobre o processo de mudança do projeto gráfico de um periódico paranaense. Utilizando conceitos do institucionalismo organizacional para a análise do caso, defende-se ser equivocada a excessiva ênfase no nível microssocial de análise para entender-se quem são os estrategistas, por esta desconsiderar a importância da dimensão institucional, sua relevância na constituição identitária desse sujeito nas organizações, e a problemática que decorre em se estudar a prática e a práxis estratégica independentemente da influência de estruturas sociais mais amplas.

Palavras-chave: Estrategistas. Praticantes. Fazer estratégico. Estratégia como prática. Institucionalismo organizacional.

\footnotetext{
Abstract

This essay analyzes who are the organizational strategists according to the 'Strategy as Practice', by disagreeing whit the methodological individualism commonly found in most of the research of the field. This argument is mainly built through empirical evidence, offering as an example a qualitative case study about the changing process of the graphic project of a journal of Paraná. Applying concepts from the organizational institutionalism literature, it is argued that the emphasis on the micro social level of analysis per se does not help to understand who are the strategists, because of the slight attention paid towards the institutional dimension, therefore missing
} 
its relevance in the constitution of the identity of those individuals in the organizations, and also its influence on the practice and praxis of strategizing..

Keywords: Strategists. Practitione. Strategizing. Strategy as Practice. Organizational Institutionalism.

\section{Introdução}

Até o presente momento, a intenção de se completar a guinada em direção à prática nas pesquisas sobre estratégia (WHITTINGTON, 2006) ainda não se concretizou conforme esperado. A sedução promovida pelo estudo das micropráticas estratégicas e a facilidade de desenvolvimento de estudos de caso único e corte temporal transversal associam-se aos obstáculos teóricos em conceber estrutura analítica que equilibre adequada e legitimamente os níveis micro e macro, os âmbitos da ação e da estrutura, a sincronia e a diacronia, enfim, o conjunto de dualismos presentes em boa parte da prática de pesquisa na área. Argumentamos que isso tem redundado na concentração das pesquisas no âmbito da práxis estratégica e em sua vinculação implícita ou explicitamente com alguma versão do individualismo metodológico, relegando a segundo plano o núcleo da proposta que seria o estudo das práticas que constituem a estratégia e que, em razão disso, até o momento não foi dada resposta satisfatória à pergunta quem são os praticantes da estratégia.

A questão relativa à definição dos responsáveis pelo desenvolvimento da prática estratégica nas organizações está presente desde os primeiros textos fundadores da perspectiva da 'Estratégia como Prática' (WHITTINGTON, 1996; 2002). Na visão de Whittington (2006, p. 619), os praticantes ou atores da estratégia podem ser definidos como [...] the strategists who both perform this activity and carry its practices. Apesar da simplicidade dessa definição, as dificuldades inerentes ao estudo adequado dos praticantes da estratégia mantêm a questão como pauta recorrente em praticamente todas as agendas de pesquisa e sugestões para investigações futuras (CARTER; CLEGG; KORNBERGER, 2008b; JARZABKOWSKI; BALOGUN; SEIDL, 2007; WHITTINGTON, 2002).

Diante dessa situação, o presente artigo propõe-se a apresentar uma revisão da questão: 'quem são os estrategistas?', no contexto das pesquisas em estratégia como prática. Após revisar as principais discussões e críticas apresentadas pelos trabalhos publicados nos últimos anos, ratificamos a necessidade de o estudo dos praticantes da estratégia ser complementado por abordagem capaz de integrar as dimensões micro e macrossociais da estratégia e desenvolvemos quadro analítico baseado na perspectiva do institucionalismo organizacional. Como forma de demonstrar a utilidade dessa proposta, buscamos oferecer evidência empírica por meio da apresentação de um estudo de caso sobre o processo de mudança do projeto gráfico de um periódico paranaense. Assim, seguem-se a essa introdução seções que: i) resgatam e discutem a figura do estrategista segundo a perspectiva da estratégia como prática; ii) propõem uma leitura alternativa para a pergunta de pesquisa colocada; e iii) ilustram e elucidam, empiricamente, os contornos dessa proposição, oxigenando caminhos para suprir lacunas teóricas desse objeto de estudo, evidenciadas na literatura predominante na área.

\section{Os Estrategistas Segundo a Estratégia como Prática}

A abordagem clássica da estratégia, associada aos trabalhos desenvolvidos por Alfred Chandler ou Igor $\mathrm{H}$. Ansoff, cujas influências são percebidas ainda hoje em autores como Michael E. Porter, atribuía a responsabilidade da realização da estratégia à elite organizacional composta da alta administração e dos estrategistas (SILVA; CARRIERI; JUNQUILHO, 2011). A corrente principal de estudos que se seguiu à escola clássica caracterizou a estratégia como processo emergente e incremental, ocupando-se da análise da influência elementos sociais e políticos e considerando a possibilidade de outros atores além de aqueles situados na cúpula da organização interferirem no fazer estratégico (CARTER; CLEGG; KORNBERGER, 2008b).

A estratégia como prática se propunha realizar grande mudança nessa visão tradicional. Afastando-se de perspectivas associadas a definições 
pré-concebidas sobre quais eram os estrategistas organizacionais, postulava que os estudos em estratégia deveriam identificar os estrategistas a partir das práticas estratégicas, conhecer suas biografias e seus percursos de desenvolvimento, as formas de educação, treinamento e desenvolvimento de seus conhecimentos práticos, as características e habilidades que os definem e os tornam mais ou menos efetivos (WHITTINGTON, 1996).

Em trabalho posterior, Whittington (2002) apresentou ampla lista que englobava diferentes conjuntos de 'trabalhadores da estratégia': gestores da cúpula da organização e também de nível médio, analistas estratégicos, especialistas em desenvolvimento organizacional, consultores de negócio, especialistas em comunicação, e também advogados e investidores. Explorando um pouco a literatura sobre esses atores, ele destacou três grupos mais relevantes: as elites gerenciais, os gestores de nível médio e também os consultores.

Naquele período, a demanda do autor estava direcionada à falta de conhecimento sobre: 1) a divisão de trabalho na produção da estratégia: a) como os atores identificados e outros potenciais participantes atuam em conjunto na criação de estratégias e b) as formas de interação e as situações a partir das quais os atores se tornam mais relevantes e capazes de influenciar de modo mais determinante a estratégia organizacional; e também 2) a produção dos responsáveis pela estratégia: a forma como as pessoas se tornam estrategistas, englobando a formação e seleção do corpo gerencial da organização, mas também o desenvolvimento educacional e de carreira dos especialistas em estratégia e organizações.

Seguindo essa exploração inicial, Clegg, Carter e Kornberger (2004) consideravam que, embora se soubesse relativamente muito sobre os ocupantes de posições profissionais, de conhecimento e consultores organizacionais, pouco ainda se sabia acerca dos estrategistas: sobre a 'matéria' da qual seriam constituídos e a 'forma' por meio da qual seriam criados. Eles chamaram a atenção para a necessidade de estudo da constituição identitária dos estrategistas: sua caracterização demográfica, a forma como eles viam a si mesmos, como construíam suas subjetividades, os processos de educação e treinamento, os ritos de passagem, entre outros elementos relacionados.

As respostas que a produção acadêmica posterior ofereceu para essas questões certamente enriqueceram os conhecimentos que se possuía à época, mas foram tendenciosas em suas aproximações da realidade empírica e insatisfatórias na proposição de quadros analíticos abrangentes. Em geral, as pesquisas desenvolvidas focaram majoritariamente na dimensão microanalítica ou microcontextual, exploraram somente alguns poucos casos e não conseguiram generalizar adequadamente proposições teóricas capazes de sustentar a formulação de abordagem ampla e integrada capaz de ser utilizada também em outros contextos (CARTER; CLEGG; KORNBERGER, 2008a; LANGLEY, 2010; WILSON; JARZABKOWSKI, 2004). Isso é especialmente relevante quando se considera o olhar da perspectiva sobre a questão dos estrategistas.

Diferentes autores se dedicaram com maior ou menor interesse em explorar a questão dos praticantes da estratégia. Em geral, os trabalhos que discutem a posição dos estrategistas no contexto da abordagem da estratégia como prática, fazem-no associadas às duas outras temáticas centrais: a práxis e as práticas (WHITTINGTON, 2006), e utilizam matizes teóricas distintas com o objetivo de oferecer compreensão mais adequada da questão. Foram identificadas na literatura quatro vertentes principais da estratégia como prática que abordaram a questão dos estrategistas, distinguidas conforme estivessem assentadas nas teorias: foucaultiana; das representações sociais; da atividade; e da estruturação. Dentre as principais críticas a que essas formulações buscam responder é possível indicar: a) praticantes da estratégia são concebidos aprioristicamente nas abordagens teóricas; b) estrategistas são normalmente associados a pessoas, entidades individuais isoladas; c) atores estratégicos são vistos como agentes competentes que voluntariamente realizam ações e tomam decisões; d) agentes da estratégia são somente aqueles que pertencem à cúpula da organização; e) atores não humanos e não atores da estratégia permanecem excluídos das análises.

As abordagens baseadas em Foucault são um dos dois eixos principais das propostas que tentaram descolar-se de visão mais voluntarista do agente da estratégia, conforme a revisão de Allard-Poesi (2010) - o segundo está vinculado à perspectiva da estruturação e tem como epítome o trabalho de Whittington (1992). 0 recurso empregado por aquele primeiro ramo envolve considerar a estratégia como sistema de 'poder-conhecimento' cujas práticas inscrevem na subjetividade dos atores a capacidade de escolher e tomar decisões, de formular planos e provocar 
mudanças e também de influenciar e controlar o comportamento de outros atores (ALLARD-POESI, 2010; KNIGHTS; MORGAN, 1991).

Embora mantendo coerência com a proposta foucaultiana, a visão dos estrategistas, que emerge a partir dessa ótica, subordina os estrategistas ao discurso da estratégia, considerando que existe pouco espaço para que eles se desvencilhem deles, preservem ou resistam à ação de construção de suas subjetividades operadas pelas práticas da estratégia. Os estrategistas se tornam, em grande parte, aquilo que as práticas e o discurso da estratégia definem que eles sejam. As práticas estratégicas são consideradas como tecnologias de controle à distância, apropriadas pela subjetividade dos estrategistas e a partir de cujas regras eles precisam desenvolver seu comportamento. Dessa maneira, são técnicas de monitoramento por meio das quais os estrategistas demonstram aos outros, exercendo sobre si mesmos o autocontrole na medida em que desvelam (unfold) os seus 'eus' (self), suas intenções, desejos e subjetividade visando a apresentá-los conformados às regras do social (ALLARD-POESI, 2010).

Partindo também de Foucault, mas integrando-o com contribuições de Serge Moscovici e Michel de Certeau, Silva, Carrieri e Souza (2012) propõem uma abordagem construcionista para se estudar a estratégia como prática. No que concerne ao nosso interesse na figura dos estrategistas, considera-se restritivo o fato de o quadro teórico não explorar dimensões mais amplas que nível dos interesses individuais e das representações sociais dos grupos. Além disso, duas situações metodológicas dificultam a análise empírica da questão: 1) o fundamento na teoria das representações sociais leva os autores a definirem como marco inicial da pesquisa a escolha dos sujeitos, mas a abordagem defendida considera que a definição dos sujeitos resulta dos lugares que ocupam e das práticas nas quais estão envolvidos; 2) a opção pela definição dos sujeitos é a resposta ao problema de delimitar aprioristicamente os níveis micro e macro da pesquisa, que os autores tentam solucionar passando a responsabilidade dos pesquisadores para os pesquisados (SILVA; CARRIERI; JUNQUILHO, 2011). No entanto, isso pressupõe por parte dos sujeitos capacidade reflexiva suficiente para manifestar em suas práticas e discursos os elementos que as influenciam e delimitam como contexto de interesse para estudo somente aquele por eles manifestado.
Outra proposta foi construída com base na 'Teoria da Atividade' (JARZABKOWSKI, 2010), apresentando uma série de pressupostos importantes para o estudo da prática estratégica nas organizações. Apesar disso, também essa proposta é incompleta na medida em que não resgata a importância da dimensão institucional para o estudo da estratégia e seus praticantes. Para essa abordagem, o estrategista é estudado a partir de determinado sistema de atividades, conforme o vínculo desse sistema com determinada coletividade. Apesar de a Teoria da Atividade ser capaz de abarcar níveis micro, meso e macro, a organização foi considerada o nível máximo para delimitação de determinado sistema de atividades. Na medida em que se postula a definição dos atores somente a partir da dinâmica das atividades, o foco se desloca excessivamente para a dimensão da práxis. Isso é tanto mais verdade quanto se verifica que a tentativa em manter-se a coerência da proposta gera situação inusitada em que se aceita a manifestação da práxis em diferentes níveis, desde níveis mais micro até o nível macro das instituições.

A quarta vertente existente na literatura buscou suporte na teoria da estruturação (GIDDENS, 2003) para informar os estudos na área de estratégia como prática. Entretanto, como outros revisores constataram, pesquisas orientadas pela teoria da estruturação tenderam a negligenciar o contexto socioestrutural, subestimando sua influência e ignorando as recomendações da teoria quanto à possibilidade de mudança estrutural (WHITTINGTON, 2010). 0 trabalho de Jarzabkowski (2008), por exemplo, referência da aplicação da teoria da estruturação para o estudo empírico da estratégia como prática, restringe o conceito de dualidade da estrutura a fenômeno interno à dimensão organizacional. Ademais, atribui a conversão nos significados, normas e dinâmica de poder nas organizações pesquisadas única e exclusivamente à atuação proativa do corpo gerencial da organização, negligenciando questões mais amplas referentes às mudanças institucionais que o campo educacional como um todo tem passado nos últimos anos (MEYER; ROWAN, 2006; MEYER et al., 1997).

Como forma de reparar essas lacunas, alguns trabalhos sugeriram a incorporação de elementos da abordagem do institucionalismo organizacional (CLEGG; CARTER; KORNBERGER, 2004; WHITTINGTON, 2006; 2010). No entanto, mesmo trabalhos recentes que pretenderam fortalecer a perspectiva da estratégia como prática a partir da 
conversação do institucionalismo organizacional e a teoria da estruturação não conseguiram equilibrar de maneira eficiente a análise da conduta estratégica com a análise institucional (CORAIOLA; MELLO; JACOMETTI, 2012). Como exemplo, o trabalho de Walter, Augusto e Fonseca (2011) que, ao alterar o conceito original de Whittington (2006), de campo extraorganizacional para campo organizacional, acabou por restringir o menu de práticas disponíveis para os estrategistas no ambiente, fragilizando a concepção de múltiplos campos e a influência de fenômenos próprios ao nível societal. No que concerne à concepção de estrategistas, mantiveram visão comum que denota o voluntarismo exacerbado atribuído à sua capacidade de escolher dentre um cardápio de opções de práticas ambientais aquelas mais convenientes de acordo com suas impressões e, se necessário, alterá-las e adequá-las aos seus contextos e interesses.

Efetuado esse balanço, podemos afirmar que concordamos com Silva, Carrieri e Souza (2012, p. 8) quando dizem que [...] in order to understand the process of strategizing in organizations, it is not enough to observe and describe the social practices of the organizational members. Apesar disso, defendemos que não é necessário recorrer a Foucault para distanciar-se de visão voluntarista do trabalho desenvolvido pelos estrategistas e que a própria base teórica que fundamenta a visão da estratégia enquanto prática social oferece elementos para se compreender a dinâmica das práticas como fenômeno situado social e historicamente. Acreditamos que boa parte desse viés não seja devido à impossibilidade de formulação teórica assentada na tradição que cria a perspectiva da estratégia-como-prática, mas decorra do posicionamento da lente do pesquisador no nível da práxis, desconectado da análise de práticas sociais, e da esposa de versão de individualismo metodológico que se manifesta no interesse generalizado em tentar compreender a práxis a partir dela mesma, ou seja, com base em determinada situação e nas motivações dos atores envolvidos em determinado intento particular.

Dessa forma, a fim de resgatar a ideia de prática social, e da compreensão dos níveis mais amplos do que a organização, optamos por retomar aos trabalhos fundamentais de Whittington, que precederam e fundamentaram a proposta de estudo da estratégia como prática social (HUNG; WHITTINGTON, 1997; WHITTINGTON, 1992; 1996; WHITTINGTON; JOHNSON; MELIN, 2004). Com base nesse resgate, mostraremos que boa parte das recomendações do autor estavam voltadas ao reconhecimento da importância da dimensão institucional e da impossibilidade de se estudarem as práticas e a práxis estratégica independentemente da influência de estruturas sociais mais amplas. Em vista disso, na seção seguinte nos dedicamos a efetuar esse resgate e demonstrar o alinhamento desta proposta aos desenvolvimentos mais recentes do institucionalismo organizacional (GREENWOOD et al., 2008). 0 ponto de partida para essa discussão reside no reconhecimento de que o elemento central que distingue a abordagem da estratégia como prática de outras perspectivas da estratégia é o fato de ela estar embasada na ideia de descentramento da organização (JARZABKOWSKI; WHITTINGTON, 2008), que remete à impossibilidade de estudo adequado dos praticantes da estratégia sem conhecimento das dimensões sociais mais amplas, como o contexto institucional no qual determinadas estratégias se desenvolvem.

\section{Articulando uma Proposta para o Estudo dos Estrategistas}

Seguindo a revisão de Allard-Poesi (2010), defendemos neste trabalho uma alternativa para a compreensão dos estrategistas a partir do segundo eixo de trabalhos que buscaram reparar as visões voluntarista da estratégia como prática. Afirma esse autor que mesmo estudando práticas localizadas, o fato de os pesquisadores nessa vertente entenderem práticas e estruturas sociais como habilitadoras e restritoras da ação não permitiu que as desconectassem da influência de outras estruturas e instituições, analisando as conexões entre práticas estratégicas localizadas e práticas sociais mais amplas, como as: familiares, políticas, profissionais, linguísticas ou organizacionais. De acordo com essa proposta, as práticas existentes tendem a ser vistas como conjuntos de recursos, capazes de serem organizados a fim de produzir uma prática distinta. Neste caso, a variedade de sistemas sociais possibilitaria aos indivíduos tanto importar regras e recursos para determinada organização, quanto promover a mudança nos sistemas de práticas nos quais elas estão baseadas (WHITTINGTON, 1992).

No entanto, esse processo tende a ser visto como não problemático. Seja em razão da propagação de visão inocente quanto à ausência de operação de 
mecanismos de dominação, poder e controle social na manutenção de determinado arranjo institucional e do conjunto de práticas a ele associado, seja devido à incorporação de certa versão da abordagem da ação racional e seu viés voluntarista, que considera a possibilidade de cálculo utilitário e decisão informada quanto ao conjunto de influências institucionais e a escolha de práticas mais adequadas ao funcionamento da organização (CARTER; CLEGG; KORNBERGER, 2008a; 2008b). 0 que os trabalhos que recorreram a Foucault buscaram demonstrar envolve a construção de edifício teórico capaz de englobar a influência da dimensão institucional sobre as práticas e a sua participação enquanto elementos constitutivos do estrategista enquanto praticante (ALLARD-POESI, 2010; SILVA; CARRIERI; SOUZA, 2012).

Consideramos, entretanto, que isso não seja estranho à própria ideia que embasa a proposta de analisar a estratégia enquanto prática social. Adotar a proposta do estudo da estratégia como prática implica considerar que boa parte dos fenômenos humanos pode ser compreendida como elementos próprios à atividade humana no mundo, ou estar a ela associados. Ao empregar a noção de atividade humana, Schatzki (In print) toma o cuidado de acrescentar que isso não significa estar assentado nas "atividades de indivíduos", mas em práticas, "nas atividades organizadas de múltiplas pessoas". A abordagem de práticas é, em sua origem, contrária a qualquer forma de individualismo metodológico. Embora a abordagem da estratégia como prática tenha enfocado a capacidade dos atores em adaptarem suas estratégias aos interesses e problemas que se manifestam em determinada situação, faz-se necessário reconhecer que essas práticas estão alicerçadas em certos princípios e propriedades estruturais (GIDDENS, 2003), regimes (ALLARD-POESI, 2010) ou arranjos de lógicas institucionais (FRIEDLAND; ALFORD, 1991), que delimitam alternativas possíveis de ação e tornam mais prováveis certas alternativas do que outras (GONÇALVES, 2007).

Nesse sentido, Allard-Poesi (2010) argumenta que somente a exploração criativa das contradições existentes entre sistemas sociais (WHITTINGTON, 1992) não é suficiente para o surgimento de novas práticas, que dependem da capacidade da estrutura de práticas existentes em assimilar práticas novas. Essas considerações remetem para a importância de exploração sistemática de determinada configuração de práticas associada a determinado locus de atividade e da análise das perturbações, rearranjos, incorporações, desagregações e desestruturações de determinado arranjo. A análise de práticas sociais não deveria encerrar-se no estudo de uma única prática ou conjunto de práticas analisado separadamente, desconectadas umas das outras, como é contumaz da maior parte dos trabalhos nessa perspectiva (JARZABKOWSKI, 2010). Visto que as práticas existem sempre enquanto 'constelações de práticas' mais ou menos permanentes, elas existem sempre integradas em rede ou como 'feixe de práticas e materialidades' (SCHATZKI, In print) que se integram, se interpenetram e se sustentam mutuamente. Nessa medida, as práticas se realizam enquanto conjuntos de atividades que ocorrem (befall) às pessoas que as desempenham, ou seja, "[...] a person performs, or carries out, the action that a performance is a performance of. But she does not perform, or carry out, the performance-the activity-itself" (SCHATZKI, In print).

Essa visão mais plural das práticas e suas associações foi de certo modo sintetizada na noção de gêneros comunicativos empregada em Silva, Carrieri e Junquilho (2011) e mais bem explicitada em Silva, Carreri e Souza (2012) com o uso de uma noção de 'mosaico de estratégias sobrepostas' para definir a existência de múltiplas estratégias simultâneas na organização, decorrentes do fluxo de práticas produzidas por meio da interação dos sujeitos organizacionais. Ela também está presente na abordagem baseada na 'Teoria da Atividade', para a qual o conceito central é a noção de 'sistema de atividades', que medeia a associação entre sujeitos, coletividades e objetivos localizados em determinado contexto histórico e cultural. De modo distinto, mas relacionado, aparece também nas formulações estruturacionistas que buscam demonstrar a conexão e interação entre práticas estratégicas organizacionais e outros conjuntos de práticas existentes em diferentes níveis de análise além da organização.

Nesse contexto, o entendimento do conceito de praticantes da estratégia mantém-se similar às outras abordagens, que entendem que "[...] it is the practices and rituals of strategy making that might constitute a person as a strategist" (CARTER; CLEGG; KORNBERGER, 2008b, p. 92), e a partir da sua manifestação que os atores "[...] shape the construction of practice through who they are, how they act and what resources they draw upon" (JARZABKOWSKI; BALOGUN; SEIDL, 2007, p. 11). Todas as abordagens 
revisadas, de uma forma ou de outra, associam uma determinada categoria de ator a determinado conjunto de ações. A partir daí é possível definir o posicionamento do ator em determinada rede de relações com outros atores e associam as práticas a ele vinculadas a uma constelação de práticas mais abrangente. Enquanto tal, as categorias e práticas pré-existem temporalmente ao envolvimento dos atores que, no entanto, ao manifestarem-nas por meio de sua práxis cotidiana, simultaneamente promovem a manutenção/transformação dessas redes de relações, significados e atribuições (GIDDENS, 2003).

$\mathrm{Na}$ perspectiva do institucionalismo organizacional, o estudo aprofundado desses encadeamentos entre práticas, significados, atores e contextos é orientado pelo conceito de lógicas institucionais (THORNTON; OCASIO, 2008), cujo objetivo principal consistiu em resgatar para a análise institucional a importância da sociedade e sua influência sobre campos organizacionais e organizações (FRIEDLAND; ALFORD, 1991). Proposta não muito distinta foi oferecida pelo próprio Whittington (1992), que argumentava quanto à necessidade de incorporar as ideias institucionalistas em uma estrutura analítica consistente e compatível com a noção de agência. A diferença é que, enquanto Whittington (1992) tentou capturar a influência das instituições sobre as organizações consolidando um conjunto de estruturas, regras e recursos em cinco tipos ideais de 'sistemas sociais', Friedland e Alford (1991) compreenderam que a influência das instituições não se concentrava em algumas esferas integradas de ação humana.

Para Friedland e Alford (1991), as sociedades são compostas por várias 'ordens institucionais' organizadas a partir de um princípio central, uma lógica institucional, constituída de práticas materiais e construtos simbólicos, que definem e delimitam tipos de campos organizacionais e organizações. "These institutional logics are symbolically grounded, organizationally structured, politically defended, and technically and materially constrained, and hence have specific historical limits" (FRIEDLAND; ALFORD, p. 248-249). Essas lógicas transpõem e organizam múltiplos domínios de atividade humana ordenados hierarquicamente, com os níveis mais amplos abrigando os mais restritos. A forma como elas se manifestam e o nível de influência que possuem na coordenação das práticas tendem a ser diferenciados, conforme a coexistência dessas normas e suas associações, contradições e arranjos em determinado contexto (THORNTON; OCASIO, 2008) e de acordo com as características do campo organizacional e organização sob análise (GREENWOOD et al., 2011).

Em nível de campo organizacional, as lógicas se apresentam em arranjos mais ou menos coesos e ordenados hierarquicamente. Elas coordenam constelações de práticas e significados e os vinculam a conjuntos de atores, recursos e relações a partir da especificação de sistemas de posição-prática. As estruturas do campo, uma vez estabelecidas, por sua vez medeiam ou 'difratam' (GREENWOOD et al., 2011) a influência das lógicas sobre as organizações. A manutenção das estruturas e, por conseguinte, a mediação da influência das lógicas é em boa parte realizada por meio da influência de certas elites e dos postos de comando por elas ocupados (ZALD; LOUNSBURY, 2010). A partir do envolvimento nessas redes de posições-práticas, esses grupos desenvolvem ações voltadas à criação, fortalecimento, manutenção ou dirupção de lógicas e estruturas institucionais existentes (LOUNSBURY; SUDDABY, 2006; REED, 2012).

A introdução e influência dessas lógicas na organização está então associada às posições ocupadas por certos grupos por elas definidos e delas mantenedores em determinados campos organizacionais e na sociedade em geral. A existência dessas elites tende a condicionar o nível de penetração de determinadas práticas e a relevância de grupos e posições dentro das organizações (GREENWOOD et al., 2011; ZALD; LOUNSBURY, 2010). Esses grupos tendem a ser majoritariamente constituídos por profissionais, e a vigência dessas lógicas se apresenta em boa parte associada ao desenvolvimento de projetos profissionais (SUDDABY; VIALE, 2011). Amparando essa arguição, destaca Scott (2008, p. 223, tradução nossa) que, na conjuntura social que se vive hoje, têm-se nas próprias atividades profissionais e nos seus agentes, legítimos condutores de instituições, dado o fato de que "[...] as profissões funcionam como agentes institucionais - como definidores, intérpretes, e aplicadores de elementos institucionais", abarcando em seu cerne a capacidade de criar e aplicar um conjunto de elementos cultural-cognitivos, normativos e/ou regulativos, desde que as condições (leia-se, as bases existentes, quer se encontrem tensionadas ou não) para que tais investidas propiciem, de alguma forma, essas manifestações (HUNG; WHITTINGTON, 1997; MEYER; JEPPERSON, 2000). 
Na visão de Clegg, Carter e Kornberger (2004), a vantagem do institucionalismo organizacional é que ele desassocia a eficácia da estratégia à sua capacidade de produção de resultados futuros diretos, relacionando-a ao fato de a estratégia constituir-se em rito organizacional legítimo e, portanto, aceito como forma racional de ação organizacional valorizada pelos stakeholders. Considerando-se o viés dessa perspectiva, poder-se-ia considerar que os estrategistas, por conseguinte, seriam os responsáveis por ministrar esse rito. No contexto dessa teoria institucionalista, os estrategistas podem ser considerados aqueles atores que em determinados contextos institucionais possuem maior legitimidade: são vistos como representação máxima ou são considerados representantes legítimos da racionalidade vigente, ou de racionalidades que se contradizem e conflitam na medida em que buscam afirmarem-se, em determinado campo organizacional. A existência dessa noção de racionalidade é resultante da influência de uma lógica institucional dominante, de lógicas híbridas ou de arranjo de lógicas que se manifestam em determinado campo organizacional (FRIEDLAND; ALFORD, 1991; GREENWOOD et al., 2011; THORNTON; OCASIO, 2008).

Seguindo os argumentos apresentados, é preciso reconhecer que a estratégia enquanto tal consiste em prática institucionalizada nas organizações, caracterizando-se como produto do trabalho de funcionários altamente especializados (WHITTINGTON, 2002). As organizações são constituídas por meio da interação entre conjuntos de atores mais ou menos organizados em distintas 'províncias de significados' (RANSON; HININGS; GREENWOOD, 1980), que estabelecem sistemas de autoridade e competência e definem a natureza, o escopo e a amplitude das atividades desempenhadas pelos membros organizacionais a partir das lógicas institucionais vigentes em determinado campo organizacional e com base em modelos e padrões de atuação aceitos como legítimos e compartilhados com outras organizações pertencentes ao mesmo setor social (SCOTT, 2008a).

Dessa maneira, estudar os estrategistas ou praticantes da estratégia não corresponde meramente à identificação de conjunto de atores individuais e grupais que em certa organização específica ou com relação à determinada prática estratégica prevaleceram sobre outros, mas consiste antes na capacidade de identificar, a partir da análise das lógicas institucionais vigentes em determinado campo organizacional, as constelações de práticas e grupos de atores que se sustentam dinâmica e mutuamente por períodos relativamente longos de tempo, capazes de imprimir com ações suas crenças e valores na estrutura e funcionamento das organizações. A partir disso, considera-se que a análise dos estrategistas leve em consideração: os conteúdos simbólicos e as práticas materiais legítimas que definem relações de posição-prática e os conjuntos de atores que a elas se vinculam e representam; as relações de contradição institucional entre lógicas, de competição organizacional e conflito grupal e individual que vivificam e (re)produzem aqueles conteúdos; e a dinâmica de mudança e manutenção desses arranjos de lógicas a partir da mobilização ativa de diferentes tipos de capital por meio do trabalho institucional (LAWRENCE; SUDDABY, 2006; SUDDABY; VIALE, 2011).

\section{Os Estrategistas no Campo das Empresas Jornalísticas Brasileiras}

A fim de demonstrarmos a utilidade da estrutura analítica aqui delineada, nos parágrafos seguintes baseamo-nos na pesquisa realizada por Coraiola (2006a; 2006b) sobre o processo de mudança do projeto gráfico do jornal paranaense Gazeta do Povo. Na pesquisa realizada foram identificados quatro grupos principais de atores envolvidos nos processos de tomada de decisão da mudança do projeto gráfico do jornal: os gestores da empresa, o grupo do marketing e comercial, os jornalistas e os designers. A mudança suscitou manifestações favoráveis e contrárias que permitiram diferenciar os posicionamentos, valores e interesses dos grupos (Quadro 1). A ideia teve origem nas conversas entre três designers do jornal, que acreditavam serem necessárias melhorias visando a tornar o texto menos poluído e a leitura mais rápida e prazerosa. Eles consultaram a diretoria quanto à possibilidade de mudança do projeto gráfico e as expectativas dela com relação ao trabalho. Desenvolveram pesquisa em jornais nacionais e internacionais, interagiram informalmente com alguns jornalistas e com a área comercial, desenvolveram análise de viabilidade e depois de seis meses apresentaram o projeto a um colegiado da empresa. Foram necessários somente alguns pequenos ajustes antes da realização de treinamentos e da implementação do projeto. 
Quadro 1 - Síntese dos posicionamentos, interesses e valores manifestos pelos grupos.

\begin{tabular}{l|l|l|l}
\hline \multicolumn{1}{c|}{ Grupos } & \multicolumn{1}{|c|}{ Posicionamento } & \multicolumn{1}{c}{ Interesses } & \multicolumn{1}{c}{ Valores } \\
\hline Gestores & Favorável & Aumentar Circulação & Comerciais/Financeiros \\
\hline Comercial/Marketing & Favorável & Aumentar Circulação & Comerciais/Financeiros \\
\hline Jornalistas & Favorável (com restrições) & Mudar Projeto Editorial & Profissionais \\
\hline Designers & Favorável & Facilitar Leitura & Profissionais \\
\hline
\end{tabular}

Fonte: os autores, 2012.

Uma análise simplificada centrada na organização consideraria que, em razão de uma redução geral na quantidade de leitores e, por conseguinte, na circulação do periódico, a solução técnica de tornar a leitura mais rápida e agradável, mostrava-se também como possível ação direcionada ao aumento da base de leitores, alinhada com os interesses dos grupos de gestores e do comercial/marketing. A divergência com os jornalistas se dava em função de estes acreditarem que a mudança de formato não era solução e que o aumento da circulação seria possível somente com maior qualidade nas matérias e reportagens. Mas como eles não tinham o poder necessário para opor-se às mudanças e para confrontar o grupo dirigente, modificou-se o projeto gráfico em detrimento do editorial. No entanto, o próprio caso apresenta indícios que restringem a validade desta interpretação: 1) as mudanças são consideradas continuação de modificações anteriores, 2) em paralelo às transformações do próprio campo das organizações jornalísticas.

A análise do campo das organizações de imprensa jornalística demonstrou que a mudança de projeto gráfico constituía caso de isomorfismo organizacional. Vários outros jornais nacionais e internacionais estavam mudando seus projetos gráficos e também nestes casos diferentes grupos se manifestavam a favor e contra essas mudanças. Analisando os discursos veiculados pela mídia, os grupos vinculados aos gestores associavam as mudanças a estratégia para ampliar a base de circulação do jornal, os designers ressaltavam os aspectos técnicos relacionados à apresentação do conteúdo e facilidade de leitura, enquanto os jornalistas se manifestavam por vezes complacentes, embora normalmente contrários às mudanças, as quais associavam a questões estéticas e não essenciais. Em conjunto a essas questões foram encontradas outras características próprias da dinâmica do campo, das quais três parecem ser as mais relevantes: 1) a profissionalização da gestão nas empresas midiáticas, em substituição à tradicional gestão familiar; 2) a informatização do processo de produção de notícias, que inverteu o processo de produção da notícia e subordinou o texto ao desenho; e 3) a permeabilidade do buffering da redação à interferência das demais áreas da empresa, que aproximou os jornalistas dos designers e dos grupos do comercial e marketing. Esses elementos sinalizam mais que simples arranjos ou coalizações de pessoas e grupos internos a uma organização na definição de questões estratégicas ou formas similares de estruturação empresarial e organização da produção jornalística no campo da mídia de jornais.

Em verdade, todas essas mudanças podem ser vistas como manifestações concretas da inversão de uma lógica eminentemente profissional derivada do jornalismo para outra lógica, de mercado, na qual uma racionalidade formal (KALBERG, 1980), orientada pela relação entre meios e fins e, por conseguinte, pelas questões econômico-financeiras e de eficiência organizacional, tende a prevalecer sobre aspectos substantivos da profissão de jornalista. Na medida em que o processo de evolução e diferenciação institucional entre as esferas do jornalismo e da imprensa clarificou as diferentes lógicas abrigadas em cada uma dessas instituições e redundou na subsunção do jornalismo à imprensa, contribuiu para a perda de relevância social do jornalismo enquanto modelo de produção da verdade e dos jornalistas enquanto representantes da opinião pública, relegando-os a papel de atores coadjuvantes no desenvolvimento das práticas estratégicas organizacionais. Simultaneamente, alçou a posições relevantes outros conjuntos de atores cuja participação até então havia sido sempre periférica. Nesse fluxo de transformações, com a institucionalização do design a atividade subordinada do desenho dos jornais passa a constituir matéria de formação profissional e habilitar a incursão de novos atores no campo. Por outro lado, o aumento da importância da circulação e distribuição dos periódicos amplia a participação de atores das áreas comercial e logística na definição de questões estratégicas da organização jornalística. 


\section{Conclusão}

A abordagem aqui defendida mantém a necessidade de definição empírica da categoria dos estrategistas organizacionais (JARZABKOWSKI; WHITTINGTON, 2008), mas considera que as abordagens que explícita ou implicitamente adotam algum modelo de individualismo metodológico são incapazes de responder adequadamente à pergunta quanto a quem são os praticantes da estratégia. Dessa maneira, o caso aqui apresentado permite reafirmar o argumento da necessidade de os estudos, que pretendem analisar a estratégia organizacional enquanto prática, ampliarem o foco da dimensão micro e olharem também para âmbitos mais amplos que a práxis desenvolvida pelos indivíduos e grupos na organização, a fim de identificar padrões e regularidades de práticas e estruturas institucionais que são mais abrangentes e condicionam aqueles identificados em determinado caso particular (GIDDENS, 2003; WHITTINGTON, 2006; 2010).

Nesse sentido, concordamos com Silva, Carrieri e Junquilho (2011) que a definição dos níveis de análise da pesquisa devem também permanecer abertos para definição empírica e deve comportar também a análise de composições e propriedades sistêmicas emergentes (JEPPERSON; MEYER, 2011), mas asseguramos que a delimitação seja estabelecida em razão dos objetivos da pesquisa e principalmente das características do fenômeno estudado, e não unicamente da percepção que dele possuem os atores selecionados para o estudo. No que concerne à análise e explicação social, argumentamos que assim como Jarzabkowski (2008) reconheceu a impossibilidade de mudança permanente na estratégia da organização sem a inscrição em nível 'institucional', de modo similar argumentamos com (JEPPERSON; MEYER, 2011) que os efeitos atribuídos aos processos de nível individual não poderiam realizar-se ou sustentar-se caso não estivessem de alguma maneira amparados em suporte institucional.

Especialmente no caso do estudo dos praticantes da estratégia ou 'estrategistas', argumenta-se que, embora seja possível identificar conjuntos de atores responsáveis pelo desenvolvimento de determinadas práticas estratégicas nas organizações, a compreensão da natureza da agência desses atores e seu estatuto perante os demais atores organizacionais não podem ser definidos única e exclusivamente com base na situação peculiar de um caso isolado e não podem ser adequadamente avaliados a menos que se conheça o histórico de estruturação e a realidade do arranjo de lógicas institucionais e da dinâmica de poder e dominação vigentes no campo organizacional no qual determinada organização se encontra imersa, assim como os processos associados de recursividade, distanciamento e integração social e de sistema que vinculam a práxis cotidiana desses atores às práticas e estruturas da longue $d u$ rée institucional (GIDDENS, 2003).

Mesmo considerando-se as dificuldades que encerram a questão do 'paradoxo da agência imersa' (BATTILANA; LECA; BOXENBAUM, 2009), considera-se que perspectivas recentes que têm explorado o papel de organizações, elites, experts e profissionais que operam na fronteiras ou em múltiplos campos e a partir de diferentes lógicas organizacionais, têm fornecido valiosos insights que apontam possibilidades de solucionar aquele paradoxo (GREENWOOD et al., 2011; SUDDABY; VIALE, 2011), embora ainda seja necessário compreender melhor os detalhes envolvidos nos processos de reflexividade e possibilidades de atuação político-cultural dos atores (CORAIOLA; JACOMETTI; BARATTER; GONÇALVES, 2012). Correlata a essa última questão, considera-se que ainda é incipiente a formulação de quadro teórico integrado o suficiente para fornecer explicação adequada quanto à emergência de novos grupos de atores institucional e a forma como eles são capazes de inserir-se e modificar lógicas e estruturas vigentes (REED, 2012).

De maneira semelhante ao que colocam Carter, Clegg e Kornberger (2008b), ao afirmar que estudar a estratégia não é simplesmente analisar o que é feito, mas também o que não é feito, o que não é dito, que não é praticado, defendemos que a análise dos espectros possíveis e prováveis de ação associados à determinada categoria social de ator em determinado contexto institucional e as formas pelas quais os modos e oportunidades de agir podem ser ampliados constituem-se em importante foco de atenção para os estudos em estratégia. Essa 'política das práticas' envolve reconhecer que as dimensões de práticas não estão cerradas e plenamente estabelecidas nos contextos institucionais, mas se configuram como espaços de interação, conflito e negociação dos atores, cujas orientações institucionais perpassam núcleos organizados de atividade humana e podem tanto apresentar-se de forma isolada e hegemônica, quanto associadas entre si, quando não se contradisserem e podendo levar à coexistência ou mudança dialética (SEO; CREED, 2002). 


\section{Referências}

ALLARD-POESI, F. A Foucauldian perspective on strategic practice: strategy as the art of (un)folding. In: GOLSORKHI, D.; ROULEAU, L.; SEIDL, D.; VAARA, E. (Ed.). Cambridge handbook of strategy as practice. Cambridge: Cambridge University Press, 2010. p.168-182.

BATTILANA, J.; LECA, B.; BOXENBAUM, E. How actors change institutions: towards a theory of institutional entrepreneurship. The Academy of Management Annals, v. 3, n. 1, 65-107, 2009.

CARTER, C.; CLEGG, S. R.; KORNBERGER, M. S-A-P zapping the field. Strategic Organization, v. 6, n. 1, p. 107-112, February 1, 2008a.

CARTER, C.; CLEGG, S. R.; KORNBERGER, M. Strategy as practice? Strategic Organization, v. 6, n. 1, p. 83-99, February 1, 2008b.

CLEGG, S.; CARTER, C.; KORNBERGER, M. 'Get up, I feel like being a strategy machine'. European Management Review, v. 1, n. 1, p. 21-28, 2004.

CORAIOLA, D. M. Agência e discurso no processo de mudança de projeto gráfico do jornal Gazeta do Povo. 223p. 2006a. Dissertação (Mestrado). Departamento de Administração, Universidade Federal do Paraná, Curitiba.

CORAIOLA, D. M. Jornalismo e Imprensa: contribuiç̃ões analíticas ao processo de institucionalização. In: CONGRESSO BRASILEIRO DE CIÊNCIAS DA COMUNICAÇÃO, 29., 2006, Brasília. Anais... São Paulo: Intercom, 2006b.

CORAIOLA, D. M.; JACOMETTI, M., BARATTER, M. A.; GONÇALVES, S. A. Trabalho Institucional e teoria da mudança gradual: reflexões sobre atores sociais, estratégias e contextos. In: ENCONTRO DE ESTUDOS ORGANIZACIONAIS, 7., 2012, Curitiba. Anais... Rio de Janeiro: ANPAD, 2012.

CORAIOLA, D. M.; MELLO, C. M. D.; JACOMETTI, M. Estruturação da estratégia como prática organizacional: possibilidades analíticas a partir do institucionalismo organizacional. Revista de Administração Mackenzie, v. 13, n. 5, set./out., 2012.

FRIEDLAND, R.; ALFORD, R. R. Bringing society back in: symbols, practices and institutional contradictions. In: POWELL, W. W.; DIMAGGIO, P. (Ed.). The New Institutionalism in organizational analysis. Chicago: University of Chicago Press, 1991. p.232-263.

GIDDENS, A. A constituição da sociedade. 2ª . São Paulo: Martins Fontes, 2003.
GONÇALVES, S. A. Mudança estratégica, esquemas interpretativos e contexto institucional: um estudo de caso longitudinal. Revista Eletrônica de Ciência Administrativa, v. 6, n. 2, 2007.

GREENWOOD, R.; OLIVER, C.; SAHLIN, K.; SUDDABY, R. Introduction. In.: GREENWOOD, R.; OLIVER, C.; SAHLIN, K.; SUDDABY, R. (Eds). The SAGE Handbook of Organizational Institutionalism. London, Thousand Oaks, CA \& New Dehli: Sage Publications, 2008, p. 1-46.

GREENWOOD, R.; RAYNARD, M.; KODEIH, F.; MICELOTTA, E. R.; LOUNSBURY, M. Institutional complexity and organizational responses. The Academy of Management Annals, v. 5, n. 1, p. 317-371, 2011.

HUNG, S.; WHITTINGTON, R. Strategies and institutions: a pluralistic account of strategies in the Taiwanese computer industry. Organization Studies, v. 18, n. 4, p. 551-575, July 1, 1997.

JARZABKOWSKI, P. Shaping strategy as a structuration process. Academy of Management Journal, v. 51, n. 4, p. 621650, August 1, 2008.

JARZABKOWSKI, P. An activity-theory approach to strategy as practice. In: GOLSORKHI, D.; ROULEAU, L.; SEIDL, D.; VAARA, E. (Ed.). Cambridge handbook of strategy as practice. Cambridge: Cambridge University Press, 2010. p.127-140.

JARZABKOWSKI, P.; BALOGUN, J.; SEIDL, D. Strategizing: the challenges of a practice perspective. Human Relations, $v$. 60, n. 1, p. 5-27, January 1, 20072007.

JARZABKOWSKI, P.; WHITTINGTON, R. Hard to disagree, mostly. Strategic Organization, v. 6, n. 1, p. 101-106, 2008.

JEPPERSON, R.; MEYER, J. W. Multiple levels of analysis and the limitations of methodological individualisms. Sociological Theory, v. 29, n. 1, p. 54-73, 2011.

KALBERG, S. Max Weber's types of rationality: cornerstones for the analysis of rationalization processes in history. American Journal of Sociology, v. 85, n. 5, p. 1145-1179, 1980.

KNIGHTS, D.; MORGAN, G. Corporate strategy, organizations, and subjectivity: A critique. Organization Studies, v. 12, n. 2, p. 251-273, April 1, 1991.

LANGLEY, A. The challenge of developing cumulative knowledge about strategy as practice. In: GOLSORKHI, D. (Ed.). Cambridge handbook of strategy as practice. Cambridge: Cambridge University Press, 2010. p.91-106. 
MEYER, H.-D.; ROWAN, B. The new institutionalism in education. Albany: State University of New York Press, 2006.

MEYER, J. W.; BOLI, J.; THOMAS, G. M.; RAMIREZ, F. O. World society and the nation-state. The American Journal of Sociology, v. 103, n. 1, p. 144-181, 1997.

MEYER, J. W.; JEPPERSON, R. L. The 'actors' of modern society: the cultural construction of social agency. Sociological Theory, v. 18, n. 1, p. 100-120, 2000.

RANSON, S.; HININGS, B.; GREENWOOD, R. The structuring of organizational structures. Administrative Science Quarterly, v. 25, n. 1, p. 1-17, 1980.

SCHATZKI, T. R. A Primer on practices: theory and research. In: HIGGS, J.; BARNETT, R., et al (Ed.). Practice-based education: Perspectives and strategies. Rotterdam: Sense, In print.

SCOTT, W. R. Institutions and organizations: ideas and interests. 3rd. Los Angeles: Sage Publications, 2008a.

SCOTT, W. R. Lords of the dance: professionals as institutional agents. Organization Studies, v. 29, n. 2, p. 219-238, February 1, 2008b.

SEO, M.-G.; CREED, W. E. D. Institutional contradictions, praxis, and institutional change: a dialectical perspective. The Academy of Management Review, v. 27, n. 2, p. 222247, 2002.

SILVA, A. R. L. D.; CARRIERI, A. D. P.; JUNQUILHO, G. S. A estratégia como prática social nas organizações: articulações entre representações sociais, estratégias e táticas cotidianas. Revista de Administração (RAUSP) da Universidade de São Paulo, v. 46, n. 2, p. 122-134, 2011.

SILVA, A. R. L. D.; SOUZA, E. M. D. A constructionist approach for the study of strategy as social practice. Brazilian Administration Review, v. 9, n. Special Edition, p. 1-18, 2012.

SUDDABY, R.; VIALE, T. Professionals and field-level change: institutional work and the professional project. Current Sociology, v. 59, n. 4, p. 423-442, 2011.

THORNTON, P. H.; OCASIO, W. Institutional logics. In: GREENWOOD, R.; OLIVER, C.; SAHLIN, K.; SUDDABY, R. (Ed.). The SAGE Handbook of organizational institutionalism. Thousand Oaks: Sage Publications, 2008. p. 99-129.
WALTER, S. A.; AUGUSTO, P. O. M.; FONSECA, V. S. D. 0 campo organizacional e a adoção de práticas estratégicas: revisitando o modelo de Whittington. Cadernos EBAPE.BR, v. 9, n. 2, p. 282-298, 2011.

WHITTINGTON, R. Putting Giddens into action. Journal of Management Studies, v. 29, n. 6, p. 693-712, 1992.

WHITTINGTON, R. Strategy as practice. Long Range Planning, v. 29, n. 5, p. 731-735, 1996.

WHITTINGTON, R. The work of strategizing and organizing: for a practice perspective. Strategic Organization, v. 1, n. 1, p. 117-125, 2002.

WHITTINGTON, R. Completing the practice turn in strategy research. Organization Studies, v. 27, n. 5, p. 613-634, 2006.

WHITTINGTON, R. Giddens, structuration theory and strategy as practice. In: GOLSORKHI, D.;ROULEAU, L., et al (Ed.). Cambridge handbook of strategy as practice. Cambridge: Cambridge University Press, 2010. p. 109-126.

WHITTINGTON, R.; JOHNSON, G.; MELIN, L. The emerging field of strategy practice: some links, a trap, a choice and a confusion. In: EGOS COLLOQUIUM, 20., 2004, Ljubljana. Proceedings... Ljubljana: EGOS, 2004.

WILSON, D. C.; JARZABKOWSKI, P. Thinking and acting strategically: new challenges for interrogating strategy. European Management Review, v. 1, n. 1, p. 14-20, 2004.

ZALD, M. N.; LOUNSBURY, M. The wizards of Oz: towards an institutional approach to elites, expertise and command posts. Organization Studies, v. 31, n. 7, p. 963-996, 2010.

Recebido: 03/08/2012

Received: 08/03/2012

Aprovado: 01/11/2012

Approved: 11/01/2012 